\title{
A PRELIMINARY STUDY ON CLASSIFICATION STANDARDS OF NATURAL RESOURCES UNDER THE INSTITUTIONAL REFORM
}

\author{
Jingjin Huang ${ }^{1}$, Zhengbei Yang ${ }^{1}$, Linghai Huang ${ }^{2}$, Yang Wang ${ }^{1}$, Jinbi Liang ${ }^{1}$, Guoqing Zhou ${ }^{3}$, Changzeng Tang ${ }^{1, *}$ \\ 1 Guangxi Institute of Natural Resources Survey and Monitoring, Nanning 530023, China; \\ 2 China University of Geosciences (Wuhan), Wuhan, 430074, China; \\ 3 Guangxi Key Laboratory of Spatial Information and Geomatics, Guilin University of Technology, Guilin 541004, China.
}

KEY WORDS: Natural resources, classification standard, institutional reform

\begin{abstract}
:
The survey and monitoring system of natural resources is the basis for finding out and monitoring the background data in the new era The classification standard is an important cornerstone in the survey and monitoring system. The classification standard appears in the whole process of natural resources, such as survey, monitoring, evaluation, planning and control etc. Classification results are widely used in natural resource asset management, territorial space use controlling, ecological protection and restoration. Therefore, only a classification standard with the unified, scientific and practical characteristics is constructed, a survey and monitoring system with "six unifications" can be built. This paper refines the existing status and the main problem of existing classification standards, and then puts forward the construction ideas and three suggestions for the new classification standards, which hoping to provide a reference for local survey and monitoring pilots and national classification standard construction.
\end{abstract}

\section{Introduction}

On November 8, 2012, the 18th National Congress of the Communist Party of China (CPC) indicated that the ecological civilization construction is contained into the "five-in-one", an overall strategic layout of the country. The ecological civilization is demanded to construct throughout the all aspects and the whole process of economic, political, cultural and social development. The ecological civilization construction is the millennium plan for sustainable development of the Chinese nation ${ }^{[1]}$, according to the report to the 19th national congress of the CPC on October 18, 2017. Therefore, Ministry of Natural Resources of China was organized to further promote the ecological civilization construction on March $2018^{[2]}$.

The basic data of natural resources are the foundation of ecological civilization construction. The nature resource was surveyed by multiple ministries respectively before the institutional reform, which result in the various surveys with different classification standard, survey methods, spatial-temporal scale and spatial overlap problems. Finally, the survey results exist lots of problems, such as mutual contradiction and hard to share. To solve these problems, Ministry of natural resources puts forward a survey and monitoring system with "six unifications" (the new system), namely, unified organization, uniform legal basis, unified survey system, unified classification standard, unified technical specification and unified data platform, which except to completely solve the problems of the results from multiple ministries, comprehensive find out the distribution of all natural resources, finally form a set of comprehensive, complete and authoritative management data to meet the needs of ecological civilization construction ${ }^{[3]}$.

Classification standard is one of the most basics and important aspects of the natural resource survey \& monitoring system. It is applied throughout the whole process of investigation, evaluation, planning, and control of natural resources ${ }^{[4]}$. The classification standard of natural resources was constructed by each ministry before institutional reform, which leads to these standards with overlapping, incompatibility, logic confusion and ambiguity. This situation has been unable to adapt to the new system. Therefore, it is urgent to re-evaluate, optimize and integrate all kinds of classification standard, and establish a unified, scientific and practical classification standard of all natural resources.

\section{2. the existing classification standard}

Before establishing a unified scientific and practical classification standard, it is necessary to analyze the present situation and mainly problems of the existing classification standard ${ }^{[4]}$. There are several major categories of classification standards under the multiple leaderships before institution reformed: (a) in the former land and resource department, there are commonly used the land management classification, the cultivated land reserve resources classification, the land planning purposes classification and the land use status classification, etc. The first class of land planning purposes is farmland, construction land, and the unutilized land. While the first class of the Third National Land and Resource Survey are wetland, plough, plant garden, woodland, grassland, commercial service land, industrial and mining land, residential land, public management and public service land, special land, transportation land, water area and water conservancy facilities land, other land; (b) in the former building and construction department, there are nine types of classification standards, such as urban residential land classification, village planning land classification, urban construction land classification, and urban and rural land classification. The first classes of urban residential land classification are residential land, public service facility land, road land and green space. The first classes of urban construction land classification are residential land, public management and public service land, industrial land, transportation facility land, etc; (c) in the former forestry department, there are 11 classification standards, in which the mainly classification standards are forest classification, forest land type, wetland classification, and forest species type. The

\footnotetext{
*Correspondence author: Changzeng Tang, Email: tcz8959@163.com
} 
forest classification has a different type in different periods, such as, in 1984, the classification type is " $5+x$ " mode, while it turned into " $2+5+23$ " mode in 2004; (d) in the former surveying and mapping department, there are land cover classification and land-surface cover classification; (e) in the national development and reform commission, there are city-county development comprehensive planning classification and economic industry classification; (f) in the livestock department, there are grassland resource classification and grassland type classification; (g) in the water resource department, there is water resources classification, in which the first class is surface water and groundwater. In sum, there are three classification situations from classification standards, namely, the classifications of the same department in the different periods, the classifications of the different departments in the same period, the classifications of the different departments in the different periods.

\subsection{The classifications of the same department in the different periods}

When one natural resource survey is conducted by one department, the targets, contents, technical levels, time-space scale, and data sources make the classification standard changing dynamically in different periods. As shown in Table1, the wetland firstly became the first class of classification in the third national land survey. This changing shows that the significance of wetland protection and indicate that an ecological concept which the landscape, forest, field, lake and grass are a community of life. Meanwhile, this changings also provide conditions for the transition for the third national land survey to the new system.

\subsection{The classifications of the different departments in the same period}

When a natural resource survey is conducted by the different departments in the same period, there are various different factors which affect the survey results, such as, the investigation tasks and product application scenarios etc. Even the survey areas, image data, time nodes, technical means are the same, the finally results are always different and hard to share. The mainly reasons are that each department has different aspects in identification of the ground objects, the land classification, the ground feature selection, etc. For example, a piece of land was identified as a uncultivated land or a wasted land by the land-resources department, while a planned forestland or a suitable forestland was defined by the forestry department, or a basic grassland which need to be protected specially was defined by the agriculture department.

In addition, a same classification has different meanings, such as a shrub land is defined with $40 \%$ coverage by the land-resource department, while the $30 \%$ coverage was defined by the forest department. The different meanings of the same classification lead to a contradictory results, such as, according to the second national land-resource survey, there were 253 million hectares of forest land in China, while the forest land quantity in seventh forest resources inventory are 195 million hectares. The gap between two surveys is about 0.6 billion hectares.

\subsection{The classifications of the different departments in the different periods}

The classification standards are diverse from each department in different periods. The mainly reasons are the differences between objects, survey technology level, temporal-spatial scales. In terms of the latitudes of time and space, the resolutions of temporal-spatial-spectral and the refinements of objects are higher and higher, the survey period is shorter and shorter, and the scope of application is more and more widely. These changes and developments make the classification standard optimize and iterate frequently.

The existing classification standards have made a great contribution to urbanization and economic development. With the development of the times, the existing classification standards exposed lots of disadvantages, which has been difficult to adapt to current land policy and ecological development concept in China.

\begin{tabular}{|c|c|c|c|c|}
\hline No & Survey types & Period (a) & Classification & Main basis and characteristics \\
\hline 1 & $\begin{array}{l}\text { The first national land } \\
\text { survey (Detailed } \\
\text { investigation) }\end{array}$ & 1984-1997 & $\begin{array}{l}8 \text { Class I, } \\
46 \text { Class II }\end{array}$ & $\begin{array}{l}\text { According to the technical regulations for survey of land use } \\
\text { status, the mainly characteristic is that the surveys in rural and } \\
\text { towns areas are separate. }\end{array}$ \\
\hline 2 & $\begin{array}{c}\text { Urban-rural cadastral } \\
\text { survey }\end{array}$ & $2001-2003$ & $\begin{array}{l}3 \text { Class I, } \\
15 \text { Class II, } \\
71 \text { Class III }\end{array}$ & $\begin{array}{l}\text { According to the national land classification (trial), the mainly } \\
\text { characteristic is that the unified management of urban and rural } \\
\text { land administration systems, which is aimed to adapt the } \\
\text { market economy and land use control. }\end{array}$ \\
\hline 3 & $\begin{array}{c}\text { The second national } \\
\text { land survey }\end{array}$ & $2007-2008$ & $\begin{array}{l}12 \text { Class I, } \\
57 \text { Class II }\end{array}$ & $\begin{array}{l}\text { According to the land use status classification, the mainly } \\
\text { characteristic is that rural land survey, urban land survey, and } \\
\text { basic farmland survey. }\end{array}$ \\
\hline 4 & $\begin{array}{l}\text { The geographical } \\
\text { conditions census }\end{array}$ & 2013-2015 & $\begin{array}{l}13 \text { Class I, } \\
61 \text { Class II, } \\
148 \text { Class III }\end{array}$ & $\begin{array}{l}\text { According to the content and indicators of geographical } \\
\text { conditions census, the mainly characteristic is that the spatial } \\
\text { distribution, characteristics and interrelationships of natural } \\
\text { and human geographic elements are conducted. }\end{array}$ \\
\hline 5 & The third national land & 2018-2019 & 13 Class I, & According to the land use status classification and the third \\
\hline
\end{tabular}




\begin{tabular}{|c|c|c|c|c|}
\hline No & Survey types & Period (a) & Classification & Main basis and characteristics \\
\hline & survey & & 55 Class II & national territorial survey classification, the mainly \\
\hline & & & & characteristic is that by land use status survey, ownership \\
\hline & & & & survey, special land survey and evaluation, and the wetland is \\
\hline & & & & adjusted to Class I. land types is determined in field to ensure \\
\hline & & & & that land types are not duplicated and not missed, full \\
\hline & & & & coverage. \\
\hline
\end{tabular}

Table 1 Classification of national surveys in different periods

\section{3. ideas of new classification standard construction}

To develop a " $1+X$ " type of the new system, the disadvantages of the existing classification standards must be solved. One of the most important step is to establish a unified, scientific and practical classification standard.

What is a unified, scientific, and practical classification standard? The unify means that the classification standards built by each departments separately were changed to be built by the natural resources uniformly. To achieve the goal of unify, the first step is breaking the barriers of each classification standards, which is not breaking these barriers mechanically. These standards need to be re-understand and re-define based on the new ecological concept. Furthermore, the classification work needs to be re-integrated and unified into the same theoretical framework.

The unify only solves the problem of barriers of the existing standards. To make the standards more science, the second step is seeking the "common" and saving the "difference". The "common" is the same part (namely, the greatest common divisor) of each standard, which is the basic index of the basic survey. The "difference" is the special part of each standard, which is the main index of the specific survey. Meanwhile, the "refining" is conducted to eliminate these indexes with the characteristics of polysemy, multi-description, blur and useless. Only to achieve the above work, the classification standard with unify and science characteristic is constructed.

If the classification standard only with unity and science characteristics, it has still not put to actual application. It also needs to make the classification with practical attributes, which requires the classification standard has the ability to continuously optimize and iterate. Only continuously optimizing and iteratively updating, the cost is continuously reduced, the efficiency is continuously improved, and the effect is more and more obvious. Only in this way, the classification standard can adapt the ecological concept and meet the application needs of natural resources survey data and results in various departments, industries and regions.

\section{SEVERAL suggestions}

The classification standard is applied to all aspects of socialist construction in China. Therefore, the construction of classification standards must have the characteristics of the times. In addition, the construction of the new classification standard is not achieved by one department. It is necessary to unite all the relevant departments and learn the strengths from others. Several suggestions are listed as follows:

(1) Following with the theme. The theme is that the mountain, forest, field, lake and grass of nature are a community of life in new era. The classification standard with the theme gene will become alive.

(2) Departments linkage. Since various departments have conducted survey and monitoring for one certain natural resource in decades, their survey data and results are widely used in the industry and in the field. The survey experiences are very rich. It is also establish a complete classification standard, technical system and application platform for one certain natural resource. By uniting the relevant departments for learning and collaborating each other, the new classification standard is constructed successfully.

(3) Pilot first. China has a vast territory, abundant natural resources and a wide variety of types, but the average per capita is rare. In particular, there are huge differences in the spatial distribution of natural resources, such as the space distribution of water resources are: Eastern is rich than Western and Southern is rich than Northern. The cultivated land resources are rich in plain basins, poor in hills and mountains, and Eastern is rich than Western. The forest resources are poor and the forest coverage is low. Most of the forest resources are concentrated in the remote mountainous areas, such as the Northeastern, Southwestern, and Southeastern hills of Taiwan. While the forest resources in the vast northwest are poor. In view of the unique time-space attributes of natural resources in China, it is necessary to carry out pilot work which can reflect the characteristics of natural resources in China. The representative pilot work provides the experiences and references for the construction of nationally unified, scientific and practical classification standard.

In 2019, Guangxi natural resources department carried out the pilot work of unified investigation and monitoring of natural resources. According to the classification of land use status (2017), this pilot attempts to classify a new classification of natural resources, which is based on the the third national land survey and the geographic national conditions monitoring. Furthermore, the characteristics of various elements of natural resources are taken into consideration, which combines specialized classification systems such as forestry resource classification, grassland classification, and wetland classification. It includes 10 Class I, including woodland, grassland, wetland, water resource and coastal zone etc., and 48 Class II. To achieve a more detailed survey and monitoring, the several classifications have expanded to Class III for more detailed. To reflect the fundamental attributes of each natural resource, the natural attributes and geographical characteristics of the natural resources are taken into consideration. Basic on the classification of land use status (2017), the land covers with the same attribute are classified into the same category by the natural attribute classification method. In the new classification, coastal zone is added, and the classification levels of grassland and wetland are also raised to Class I, which reflects the concept of natural ecological attributes and the characteristics of natural resources in Guangxi. Finally, this classification can provide a reference for the Ministry of Natural Resources to compile the national natural resources classification. 


\section{Conclusion}

The classification standards are applied throughout the whole process of investigation, evaluation, planning, and control of natural resources. Therefore, the classification standards, which have the characteristics of unify, science, and utility, need to be firstly constructed. Then the new survey and monitoring system can provide the essential data for the natural resource management. This paper refines the existing status and the mainly problem of the existing classification standards. Then the some construction ideas and several suggestions are puts forward as follows, which hope that this work of the paper can provide a reference for the local survey and monitoring pilots and national classification standards construction.

\section{ACKNOWLEDGEMENTS}

This work is financially supported by the Fourth Batch of Guangxi Academician Workstation in which the construction unit is Guangxi Institute of Geographical Conditions Monitoring and the Academician is Jiancheng Li who works in Wuhan University) (Serial Number: GuiKeChengZi [2018]121), and the National Natural Science of China under Grant numbers 41601365 .

\section{REFERENCES}

Gu, Z., Xie, Y., 2017. The. Development and Innovation of Xi Jinping's Socialism Thought with Chinese
Characteristics-Based on the Bibliometric Analysis of the Report of the 18th National Congress of the Communist Party of China and the 19th National Congress of the Communist Party of China. Journal of Gansu Administration Institute, (06): 21-30+125-126.

Dong, Y., 2018. Reflections on the Mission of Natural Resources in the New Era. Land and Resources, (04): 13-17. $\mathrm{Li}, \mathrm{Q}$., 2018. China will build a unified survey and monitoring system for natural resources. Land and Resources, (08): 14-15.

Wang X., Gong J., 2018. Evaluation and integration of land use classification standard for unified management of natural resources. 2018 Proceedings of China Land Resources Science Innovation and Development and Mr. Ni Shaoxiang's Academic Thoughts, 439-456.

Yan Y., 2018. Break down barriers and build a unified investigation system for natural resources: Research on the status and development of natural resources investigation with cross-border innovative thinking. Beijing City Planning \& Construction Review, (06): 37-40.

Zhou, D., 2016. Discussion on the Conflict between Forest Land Identification and the "One Map of Woodland" and the Co-opetition Discussion-Taking Forestry Department and Land Department Identification as an Example. Practical Forestry Technology, (09): 81 